\title{
The association between obesity and height in adolescents
}

\author{
MAHSA MEHRDAD ${ }^{1, A-G}$, PARMIS HASSANBEIGI2, A-G, GOHAR SEDAGHAT ${ }^{2, A-D}$, \\ MARYAM GHOLAMALIZADEH ${ }^{3, E, F}$, MOHAMMAD HASSAN EFTEKHARI ${ }^{1, A-G}$ \\ ORCID ID: 0000-0001-8289-8819
}

\author{
${ }^{1}$ Department of Clinical Nutrition, School of Nutrition and Food Sciences, Shiraz University of Medical Sciences, \\ Shiraz, Iran \\ ${ }^{2}$ School of Nutrition and Food Sciences, Shiraz University of Medical Sciences, Shiraz, Iran \\ ${ }^{3}$ Student Research Committee, Cancer Research Center, Shahid Beheshti University of Medical Sciences, Tehran, \\ Iran
}

A - Study Design, B - Data Collection, C - Statistical Analysis, D - Data Interpretation, E - Manuscript Preparation, F - Literature Search, G - Funds Collection

Summary Background. The prevalence of childhood obesity is increasing worldwide and can affect their linear growth through various mechanisms.

Objectives. We aimed to investigate the association between obesity-related traits and height in adolescents.

Material and methods. This was a categorized cross-sectional study carried out on 186 students (93 case and 93 control) 15 to 18 years of age who were randomly selected from three schools in Shiraz, Iran. Anthropometric indices including height, weight, body mass index (BMI), body fat percentage (BF) and body muscle percentage (BM) were measured. Statistical analysis was done by SPSS software (Version 16). A significance level was considered as being less than 0.05 .

Results. We found an inverse association for waist circumference (WC) and fat mass with height. In addition, there was a direct relationship between fat-free mass and trunk fat with height. The mean height of participants in the obesity group was significantly lower than the control group $(p=0.04)$. Participants in the obesity group had significant higher FM percentage $(p<0.001)$ and WC $(p<0.001)$ than the control group. There was a significant correlation between height and WC $(p=0.003)$, as well as between height and fat percentage $(p<0.001)$. We also found a direct relationship between fast-free mass and height $(p<0.001)$, as well as between trunk fat percentage and height $(p=0.026)$. We have suggested an equation to estimate adolescents' height based on the anthropometric indices. Conclusions. Adiposity, especially central adiposity, is adversely associated with height. However, muscle percentage might reinforce linear growth. Further studies are warranted to confirm this finding.

Key words: obesity, body height, growth, adolescent, body fat distribution.

Mehrdad M, Hassanbeigi P, Sedaghat G, Gholamalizadeh M, Eftekhari MH. The association between obesity and height in adolescents. Fam Med Prim Care Rev 2021; 23(3): 318-322, doi: https://doi.org/10.5114/fmpcr.2021.108197.

\section{Background}

Human growth is a complex process impacted by interactions between genetic and environmental factors, as well as lifestyle. Approximately $60-80 \%$ of variation in height among adolescents is determined by genetic factors [1, 2], while $20-40 \%$ can be attributed to environmental factors, such as over-nutrition, which leads to obesity. Although the process of growth and maturing in obese children is faster than others, their final height would be shorter [3, 4]. The global epidemic of early obesity has raised the interest in understanding the causes and consequences of obesity [5, 6]. Factors affecting child growth in obese children include increased leptin and insulin levels, adrenal androgens, insulin-like growth factor (IGF)-1, IGF-binding protein-1, GH-binding proteins, as well as reduced secretion of growth hormone [6, 7].

There have been various studies conducted to assess the effect of obesity on height. A cohort study on 1,901 participants 3.5-8 years of age reported that higher childhood body mass index (BMI) was associated with higher growth parameters before onset of puberty and earlier puberty [8]. Bratberg et al. conducted a study on children 12-16 years of age in middle schools and claimed that early maturation in girls leads to shorter height compared to normal maturated girls [9]. Shalitin et al. claimed that growth rate in overweight adolescents is slower than their normal-weight peers [10], and other studies found that body frame size and shape in children was associated with the amount of adipose tissue in different adipose tissue depots but not with adipose distribution $[11,12]$. Some studies suggested a relationship for multiple adiposity-associated-genetic loci with pubertal timing and adult height and also confirmed that despite hormonal change in obesity, molecular pathways are also involved in linear growth regulation [13-16]. Many factors could have an influence on obesity and disease in children. These could have an influence on the anthropometric index [17-19].

As mentioned above, studies have produced controversial results, and most of them were performed in childhood and pre-puberty ages, and less is done regarding the association between obesity and linear growth in adolescents. In addition, it is better to select more suitable indices to assess obesity, such as fat mass (FM) and central obesity. Therefore, due to the fact that $\mathrm{BMI}$ creates a bias and does not distinguish between fat tissue and fat-free mass [20], waist circumference (WC) and waist-to-height ratio $(\mathrm{W} / \mathrm{Ht})$ are suggested as the most popular indices to measure central obesity [21].

\section{Objectives}

This study aimed to investigate the association of obesity-related traits with height in adolescents. 


\section{Material and methods}

We conducted a categorized cross-sectional study to determine the association between obesity-related traits and height in adolescents 15-18 years of age. Sample size (93 cases and 93 controls) was determined with alpha 0.05 and a power of 0.80 .

Ethical approval was obtained from Shiraz University of Medical Sciences. Written informed consent was obtained from all the participants. They were recruited between March and April 2017 from three different socio-economic level schools of Shiraz, Iran. The participants attended a single study session. A prepared questionnaire was completed, including demographics and anthropometrics data. Healthy adolescents with excess and normal body fat percentage were categorized in two groups; FM more than $30 \%$ for girls and more than $25 \%$ for boys were considered as excess fat percentages. Individuals with lower body fat percentage (less than 15\% for girls and less than $10 \%$ for boys) were excluded.

Since, in our study, height is a dependent variable, we used WC instead of waist-to-height ratio as an indicator of central obesity for controlling bias and misinterpretation [22]. In addition, WC is less correlated with the timing of sexual maturation than BMI [9]. We also involved both genders, because after the age of 14 , the difference in magnitude of linear rate between genders is negligible [23].

\section{Measurements}

The participants were asked not to consume excessive amounts of food and water or perform vigorous-intensity activity one day before anthropometric assessment. Height as a dependent variable was measured by a non-stretch tape. Weight, FM, fat-free mass (FFM) and trunk fat were measured by bioelectrical impedance analyzer (Tanita, Japan/BC-418). WC was measured between the edge of the ribs and iliac spine. BMI was calculated by the equation: weight $(\mathrm{kg}) /$ height $\left(\mathrm{m}^{2}\right)$.

\section{Statistical analysis}

The results are expressed as mean (SD). The Shapiro-Wilk test was used to test the normality of the distribution of variables. Residual normality, co-linearity of variables and independency of variables were also checked and confirmed. The Chi-square test was used to confirm gender matching, and the $t$-Test was used to confirm age matching. Backward linear regression analysis was performed to investigate the association of height and obesity-related traits after controlling the confounding factors of age, gender, BMI and weight. A $p$-value less than 0.05 was considered to be statistically significant. All statistical analyses were carried out using the statistical software SPSS, Version 16

\section{Results}

186 participants were enrolled in this study. 93 adolescents with excess body fat percentage (Category $1 ; \mathrm{C} 1$ ) and 93 gender- and age-matched adolescents (Category 2; C2) with normal body fat percentage were allocated in the two categories. There were no differences for age (C1: $16.9(0.8)$ vs C2 16.9 (0.8), $t$-Test; $p=0.44$ ) between the two categories. Mean obesity traits were significantly higher in individuals with the category of excess body fat percentage than the other (Table 1). The mean height of participants in group C1 was significantly lower than in group C2 (166.4 (18.7) vs 170.3 (9.8); $p=0.04)$. Participants in group $\mathrm{C} 1$ had a significant higher FM percentage (31.8 (6.3) vs $18.2(5.4) ; p<0.001)$ and WC (90.6 (12.7) vs 74.4 (7.4); $p<0.001)$ than in C2. Table 1 shows the demographic and anthropometric characteristics for both study groups.

Although anthropometric data did not have normal distribution, assumption of a normal distribution of residual variance for regression analysis was not violated. Backward regression analysis suggested three models for the equation, but we only included significant indices of the third model in the final equation. Significant correlations were observed between height and waist circumference (WC) $(-0.258 ; p=0.003$; Confidence Inter-

\begin{tabular}{|c|c|c|c|c|c|}
\hline & $n$ & Mean (SD) & Minimum & Maximum & $p$ \\
\hline $\begin{array}{l}\text { Age }(y r s) \\
\text { case } \\
\text { control }\end{array}$ & $\begin{array}{l}93 \\
93 \\
\end{array}$ & $\begin{array}{l}16.9(0.8) \\
16.9(0.8) \\
\end{array}$ & $\begin{array}{l}16.0 \\
16.0 \\
\end{array}$ & $\begin{array}{l}18.0 \\
18.0 \\
\end{array}$ & 0.44 \\
\hline $\begin{array}{l}\text { Weight }(\mathrm{kg}) \\
\text { case } \\
\text { control }\end{array}$ & $\begin{array}{l}93 \\
93\end{array}$ & $\begin{array}{l}79.3(16.8) \\
59.4(11.4)\end{array}$ & $\begin{array}{l}55.5 \\
22.8\end{array}$ & $\begin{array}{l}122.5 \\
95.2\end{array}$ & $0.01 *$ \\
\hline $\begin{array}{l}\text { Height }(\mathrm{cm}) \\
\text { case } \\
\text { control }\end{array}$ & $\begin{array}{l}93 \\
93 \\
\end{array}$ & $\begin{array}{l}166.4(18.7) \\
170.4(9.9)\end{array}$ & $\begin{array}{l}167 \\
150\end{array}$ & $\begin{array}{l}195 \\
196 \\
\end{array}$ & $0.04 *$ \\
\hline $\begin{array}{l}\text { BMI }\left(\mathrm{kg} / \mathrm{m}^{2}\right) \\
\text { case } \\
\text { control }\end{array}$ & $\begin{array}{l}93 \\
93 \\
\end{array}$ & $\begin{array}{l}37.3(1.1) \\
20.4(2.9) \\
\end{array}$ & $\begin{array}{l}19.9 \\
19.4 \\
\end{array}$ & $\begin{array}{l}37.0 \\
27.3 \\
\end{array}$ & $0.03 *$ \\
\hline $\begin{array}{l}\text { Waist circumference }(\mathrm{cm}) \\
\text { case } \\
\text { control }\end{array}$ & $\begin{array}{l}93 \\
93\end{array}$ & $\begin{array}{l}90.6(12.7) \\
74.4(7.4)\end{array}$ & $\begin{array}{l}65 \\
62 \\
\end{array}$ & $\begin{array}{l}133 \\
103\end{array}$ & $0.01 *$ \\
\hline $\begin{array}{l}\text { Fat mass }(\%) \\
\text { case } \\
\text { control }\end{array}$ & $\begin{array}{l}93 \\
93\end{array}$ & $\begin{array}{l}31.8(6.3) \\
18.2(5.4)\end{array}$ & $\begin{array}{l}20.5 \\
10.2\end{array}$ & $\begin{array}{l}48.1 \\
29.8\end{array}$ & $0.01 *$ \\
\hline $\begin{array}{l}\text { Fat-free mass }(\mathrm{kg}) \\
\text { case } \\
\text { control }\end{array}$ & $\begin{array}{l}93 \\
93 \\
\end{array}$ & $\begin{array}{l}53.7(12.6) \\
48.8(9.9)\end{array}$ & $\begin{array}{l}36.3 \\
34.0 \\
\end{array}$ & $\begin{array}{l}81.3 \\
69.7 \\
\end{array}$ & $0.03 *$ \\
\hline $\begin{array}{l}\text { Trunk fat (\%) } \\
\text { case } \\
\text { control }\end{array}$ & $\begin{array}{l}93 \\
93\end{array}$ & $\begin{array}{l}30.3(6.6) \\
15.4(5.4)\end{array}$ & $\begin{array}{l}16.3 \\
7.6\end{array}$ & $\begin{array}{l}48.6 \\
31.0\end{array}$ & $0.01 *$ \\
\hline
\end{tabular}

$t$-Test was used to compare means between the groups. Both groups were well-matched for age; ${ }^{*} p$-value less than 0.05 means a significant difference; BMI - body mass index. 


\begin{tabular}{|l|l|l|l|l|}
\hline \multicolumn{3}{|l|}{ Table 2. Correlation between each independent variable and height as a dependent variable } \\
\hline Models & Variables & Beta** & $\boldsymbol{p}^{*}$ & $95 \%$ Confidence Interval \\
\hline Model 1 for height correlations & WC & -0.247 & 0.004 & -0.321 to -0.061 \\
& FM\% & -0.347 & $<0.001$ & -0.542 to -0.192 \\
& BMR & -0.098 & 0.225 & -0.008 to 0.002 \\
& FFM & 0.991 & $<0.001$ & 0.723 to 1.063 \\
& TBW & -0.033 & 0.395 & -0.042 to 0.017 \\
& Trunk Fat\% & 0.156 & 0.030 & 0.015 to 0.290 \\
\hline Model 2 for height correlations & WC & -0.249 & 0.004 & -0.323 to -0.063 \\
& FM\% & -0.345 & $<0.001$ & -0.539 to -0.190 \\
& BMR & -0.098 & 0.222 & -0.008 to 0.002 \\
& FFM & 0.983 & $<0.001$ & 0.716 to 1.055 \\
& Trunk Fat\% & 0.157 & 0.029 & 0.016 to 0.291 \\
\hline Model 3 for height correlations & WC & -0.258 & 0.003 & -0.330 to -0.070 \\
& FM $\%$ & -0.361 & $<0.001$ & -0.554 to -0.209 \\
& FFM & 0.902 & $<0.001$ & 0.690 to 0.935 \\
& Trunk Fat\% & 0.160 & 0.026 & 0.019 to 0.294 \\
\hline
\end{tabular}

Simple linear regression was used to control confounding and to find independent correlations between each variable and the main dependent variable (height).

* $p$-value less than 0.05 means a significant correlation between the variable and height; ** B coefficient shows the direction and magnitude of correlation between the variable and height; WC - waist circumference; FM\% - fat mass percentage; BMR - basal metabolic rate; FFM - fat-free mass; TBW - total body water.

val ( $\mathrm{Cl}):-0.330$ to -0.070$)$, as well as between height and fat percentage $(-0.361 ; p<0.001 ; \mathrm{Cl}:-0.542$ to -0.192$)$. We also found a direct relationship between FFM and height $(0.902 ; p<0.001$; $\mathrm{Cl}$ : 0.690-0.935), as well as between trunk fat percentage and height (0.160; $p=0.026 ; \mathrm{Cl}: 0.019-0.294)$. Hence, we can suggest an equation according to results shown in Table 2 as follow:

Height $\mathrm{cm}=149.9-0.258\left(\mathrm{WC}_{\mathrm{cm}}\right)-0.361\left(\mathrm{FM}_{\%}\right)+0.902\left(\mathrm{FFM}_{\mathrm{kg}}\right)$ +0.160 (Trunk fat ${ }_{\%}$ ).

\section{Discussion}

Our study found that excess fat mass, specifically excess abdominal fat, during adolescence might limit linear growth, so that each unit increase in WC is associated with an increase of $0.258 \mathrm{~cm}$ in height, and each unit increase in FM is associated with a decrease of $0.361 \mathrm{~cm}$ in height. Besides this, we observed that each unit increase in trunk fat is associated with an increase of $0.160 \mathrm{~cm}$ in height. This direct relationship, despite the inverse relationship of FM and WC with height, implicated that adiposity in different parts of the body might have various effects on linear growth. In addition, this study found a direct association between FFM and height, so that each unit increase in FFM is associated with an increase of $0.902 \mathrm{~cm}$ in height. However, the relationship between FFM and height could be reciprocal, since taller individuals have greater amounts of FFM, and higher amounts of FFM can also improve an individual's linear growth.

One study claimed that excess FM can attenuate GH secretion and decrease the half-life of $\mathrm{GH}$, even in children treated with exogenous $\mathrm{GH}$. The underlying mechanism is not well understood; however, they suggested the role of peripheral factors, like leptin, IGF-1 and insulin, as well as central hypothalamic/pituitary modulators [24]. IGF-1 is a potential suppressor for $\mathrm{GH}$. In addition, diet has been implicated as a regulator of IGF-1 levels so higher calorie intake and obesity can increase the level of IGF-1 $[25,26]$. Hyperinsulinemia, as a result of insulin resistance in central obesity, has a direct inhibitory effect on pituitary GH synthesis and release [24]. We know that obesity is associated with central resistance to circulating leptin, hence the effect of leptin as a skeletal growth factor, and the stimulatory effect on GH secretion is decreased in obesity [27]. As shown previously, central obesity is a critical cause for leptin and insulin resistance [28], hyperinsulinemia and reduced plasma GH levels in comparison with general obesity.

Aksglaede et al. [29] conducted a cross-sectional study on 156,835 children who attended primary school from 1930-1969 to find a relationship between BMI and pubertal timing. They found that boys and girls entered puberty earlier independent of their BMI level. They suggested that the obesity epidemic is not solely responsible for a downward trend in the age at attaining puberty in both boys and girls. Lee et al. [30] studied the relationship of weight status with the timing of puberty in boys. They reanalyzed recent community-based pubertal data from the American Academy of Pediatrics' Research in Office Settings, in which trained clinicians assessed boys 6 to 16 years of age for height, weight, Tanner stages, testicular volume (TV) and other pubertal variables. They reported later puberty for obese boys compared with normal and overweight boys. The inconsistency between these conclusions might be due to using BMI in their studies [31]. We believe that if they had designed their study in a better way to evaluate body fat content and distribution, they would have reached a better conclusion implicating that the downward trend might be due to increasing body FM, especially central adiposity.

$\mathrm{He}$ and Karlberg [32] suggested that over-nutrition in individuals 2-8 years of age would not be favorable with respect to final height, since the temporary increase in height gain during childhood is compensated for by earlier pubertal maturity and subnormal height gain during adolescence. They found that each unit increase in BMI was associated with an increase of $0.23 \mathrm{~cm}$ in height for boys and $0.29 \mathrm{~cm}$ for girls.

Puberty timing was also earlier by $0.6 \mathrm{y}$ in boys and 0.7 $\mathrm{y}$ in girls. Each unit increase in $\mathrm{BMI}$ in childhood reduces the height gain in adolescence by $0.88 \mathrm{~cm}$ for boys and $0.51 \mathrm{~cm}$ for girls. Another study was performed by Komlos and Breitfelder according to NHANES surveys (1999-2004) that compared the height and BMI values of US children and adolescents to their Dutch counterparts and found that the US children and adolescents were both shorter and heavier than their Dutch counterparts. They stated that a positive energy balance might lead to a higher tempo of growth in childhood and an earlier cessation of growth in adolescence. They also claimed that biologically relevant estradiol levels increase GH release and IGF-1 levels and lead to the commencement of the pubertal growth spurt, which occurs at a younger age in girls than in boys and is possibly more notable at an earlier stage of puberty in girls. For boys, this pathway is the same, so estradiol increases GH levels and the pubertal growth spurt. Estrogen levels are linked to testosterone concentration and hence to the time of peak growth rate. Consequently, continuous exposure to estrogen causes epiphyseal fusion and subsequent slower growth in ado- 
lescence [33]. The findings of the two mentioned studies were partially in line with the present study. However, our results indicated the importance of fat distribution in addition to the importance of general obesity.

A cross-sectional study by Zapata et al. [34] in adults 18-70 years of age found that the prevalence of short stature was associated with abdominal obesity. Despite the consistency with our findings, theirs might be biased, as they collected data from the adult population. It is possible that a tall adult might become obese; therefore, adolescence is a better choice for studying this relationship.

Several other studies showed that linear growth in obese adolescents is slower than their lean peers [35], even with a genetic height potential [36]. Our study added a novel and interesting finding to this area of research, namely that fat distribution is more important than general obesity when it comes to linear growth. It should be considered that a thin individual with normal BMI or FM could have excess abdominal fat, which is a risk factor not only for metabolic outcomes [37-39] but also for optimum linear growth and development at younger ages. On the other hand, fat deposition in breasts might have a protective effect on linear growth. Our recommended equation also estimates the approximate height in adolescence based on these indices: WC, FM percentage, Trunk fat percentage and FFM. Therefore, in order to diagnose the type of obesity and its effects on growth during early growth ages, we should also consider the indices of body composition in combination. Hence, we should use markers of fat distribution, such as WC, waist-to-hip ratio and waist-to-height ratio in combination with assessing total FM, FFM, BMI and weight with accurate tools.

\section{Limitations and strengths of the study}

Our study had several limitations. First, we used statistical tests to control the confounders, thus a possibility of other unrecognizable confounders cannot be ruled out. Second, the BIA system used in our study, despite its accurateness in clinical application, might have some errors, and thus, other methods, such as DXA, is suggested for better assessment of FM amount and its distribution in further research.

As for the strengths of our study, we mainly selected true obesity traits, such as WC, which is an index for chronic poor eating habits and obesity rather than other traits. We can conclude that abdominal obesity over a long period can have adverse effects on linear growth. Additionally, we selected participants from three different schools in different socio-economic districts, which reduced the probability of bias. The adolescent population was also a better choice than children, since there is a positive association between childhood obesity and linear growth, and this can cause the misunderstanding that individuals with obesity will grow to be taller. Finally, we matched two groups for gender, and we could generalize the results for both girls and boys.

\section{Conclusions}

This study suggests that fat distribution is as important as general fatness. Adolescents with abdominal obesity might have slower and less height gain compared with the adolescents with normal abdominal fat. On the other hand, fat deposition in other parts of the trunk, except for the abdominal region, might not limit linear growth. According to our recommended equation, we should consider FM and FFM in combination with indices of fat distribution to better describe the effects of obesity on linear growth. Further studies should be conducted to confirm and improve our findings and equation.

Acknowledgments. The authors kindly thank all the participants and authorities who cooperated with this study.

Source of funding: This work was funded from the authors' own resources.

Conflicts of interest: The authors declare no conflicts of interest.

\section{References}

1. Perola M. Genetics of human stature: lessons from genome-wide association studies. Horm Res Paediatr 2011; 76(Suppl. 3): 10-11.

2. Kalantari N, Doaei S, Gordali M, et al. The association between dairy intake, simple sugars and Body Mass Index with expression and extent of anger in female students. Iran J Psychiatry 2016; 11(1): 43-50.

3. Marcovecchio ML, Chiarelli F. Obesity and growth during childhood and puberty. World Rev Nutr Diet 2013; 106: $135-141$.

4. Doaei S, Gholamalizadeh M, Entezari MH. Maternal self-efficacy and feeding practices in children aged 3-6 years. Iran J Psychiatry 2015; 10(4): 278-284.

5. Fennoy I. Effect of obesity on linear growth. Curr Opin Endocrinol Diabetes Obes 2013; 20(1): 44-49.

6. Doaei S, Malmir H, Kalantari N, et al. Body Mass Index (BMI) was associated with mental health, but it had no association with selfesteem in Iranian girls: a case-control study. Acta Med Mediterr 2018; 34(4): 1017-1025.

7. Williams MC, McMillan CJ, Snead ER, et al. Association of circulating adipokine concentrations with indices of adiposity and sex in healthy, adult client owned cats. BMC Vet Res 2019; 15(1): 332.

8. Holmgren A, Niklasson A, Nierop AF, et al. Pubertal height gain is inversely related to peak BMI in childhood. Pediatr Res 2017; 81(3): 448-454.

9. Bratberg GH, Nilsen TI, Holmen TL, et al. Combined influence of early sexual maturation and central adiposity on subsequent stature. A four-year follow-up of 1,605 Norwegian boys and girls: the Young-HUNT study. Eur J Pediatr 2006; 165(11): 787-793.

10. Shalitin S, Phillip M. Role of obesity and leptin in the pubertal process and pubertal growth - a review. Int J Obes Relat Metab Disord 2003; 27(8): 869-874

11. Kalantari N, Mohammadi NK, Rafieifar S, et al. Indicator for success of obesity reduction programs in adolescents: body composition or body mass index? Evaluating a school-based health promotion project after 12 weeks of intervention. Int J Prev Med 2017 ; 8: 73.

12. Guzman-de la Garza FJ, Gonzalez Ayala AE, Gomez Nava M, et al. Body frame size in school children is related to the amount of adipose tissue in different depots but not to adipose distribution. Am J Human Biol 2017; 29(5). doi: 10.1002/ajhb.23014.

13. Kalantari N, Mohammadi NK, Izadi P, et al. A complete linkage disequilibrium in a haplotype of three SNPs in Fat Mass and Obesity associated (FTO) gene was strongly associated with anthropometric indices after controlling for calorie intake and physical activity. BMC Med Genet 2018; 19(1): 146, doi: 10.1186/s12881-018-0664-z.

14. Cousminer DL, Berry DJ, Timpson NJ, et al. Genome-wide association and longitudinal analyses reveal genetic loci linking pubertal height growth, pubertal timing and childhood adiposity. Hum Mol Genet 2013; 22(13): 2735-2747.

15. Kalantari N, Mohammadi NK, Izadi P, et al. A haplotype of three SNPs in FTO had a strong association with body composition and BMI in Iranian male adolescents. PLOS ONE 2018; 13(4): e0195589, doi: 10.1371/journal.pone.0195589. 
16. Doaei S, Kalantari N, Mohammadi NK, et al. Macronutrients and the FTO gene expression in hypothalamus; a systematic review of experimental studies. Indian Heart J 2017; 69(2): 277-281.

17. Doaei S, Hajiesmaeil M, Aminifard A, et al. Effects of gene polymorphisms of metabolic enzymes on the association between red and processed meat consumption and the development of colon cancer; a literature review. J Nutr Sci 2018; 7: e26, doi: 10.1017/ jns.2018.17.

18. Shidfar F, Bahrololumi SS, Doaei S, et al. The effects of extra virgin olive oil on alanine aminotransferase, aspartate aminotransferase, and ultrasonographic indices of hepatic steatosis in nonalcoholic fatty liver disease patients undergoing low calorie diet. Can J Gastroenterol Hepatol 2018; 2018(4): 1-7.

19. Gholamalizadeh M, Doaei S, Akbari ME, et al. Influence of fat mass-and obesity-associated genotype, body mass index, and dietary intake on effects of iroquois-related homeobox 3 gene on body weight. Chin Med J (Engl) 2018; 131(17): 2113-2122.

20. Freisling $\mathrm{H}$, Arnold $\mathrm{M}$, Soerjomataram I, et al. Comparison of general obesity and measures of body fat distribution in older adults in relation to cancer risk: meta-analysis of individual participant data of seven prospective cohorts in Europe. Br J Cancer 2017; 116(11): 1486-1497.

21. Brambilla $\mathrm{P}$, Bedogni $\mathrm{G}$, Heo $\mathrm{M}$, et al. Waist circumference-to-height ratio predicts adiposity better than body mass index in children and adolescents. Int J Obes (Lond) 2013; 37(7): 943-946.

22. Salvatori R. Growth hormone deficiency in patients with obesity. Endocrine 2015; 49(2): 304-306.

23. Stovitz SD, Demerath EW, Hannan PJ, et al. Growing into obesity: patterns of height growth in those who become normal weight, overweight, or obese as young adults. Am J Hum Biol 2011; 23(5): 635-641.

24. Dichtel LE, Bjerre M, Schorr M, et al. The effect of growth hormone on bioactive IGF in overweight/obese women. Growth Hormone \& IGF Research 2018; 40: 20-27.

25. Young NJ, Metcalfe C, Gunnell D, et al. A cross-sectional analysis of the association between diet and insulin-like growth factor (IGF)-I, IGF-II, IGF-binding protein (IGFBP)-2, and IGFBP-3 in men in the United Kingdom. Cancer Causes Control 2012; 23(6): 907-917.

26. Marwaha RK, Garg M, Gupta S, et al. Assessment of insulin like growth factor-1 and IGF binding protein-3 in healthy Indian girls from Delhi and their correlation with age, pubertal status, obesity and thyroid hormonal status. J Pediatr Endocrinol Metab 2017; 30(7): 739-747.

27. Shalitin S, Kiess W. Putative effects of obesity on linear growth and puberty. Horm Res Paediatr 2017; 88(1): 101-110.

28. Carmo Martins M, Faleiro LL, Fonseca A. Relationship between leptin and body mass and metabolic syndrome in an adult population. Revista Portuguesa de Cardiologia (English Edition) 2012; 31(11): 711-719.

29. Aksglaede L, Juul A, Olsen LW, et al. Age at puberty and the emerging obesity epidemic. PLoS ONE 2009; 4(12): e8450.

30. Lee JM, Wasserman R, Kaciroti N, et al. Timing of puberty in overweight versus obese boys. Pediatrics 2016; 137(2): e20150164.

31. Franco LP, Morais CC, Cominetti C. Normal-weight obesity syndrome: diagnosis, prevalence, and clinical implications. Nutr Rev 2016; 74(9): 558-570.

32. He Q, Karlberg J. BMI in childhood and its association with height gain, timing of puberty, and final height. Pediatr Res 2001; 49(2): 244-251.

33. Komlos J, Breitfelder A. Are Americans shorter (partly) because they are fatter? A comparison of US and Dutch children's height and BMI values. Ann Hum Biol 2007; 34(6): 593-606.

34. Zapata ME, Bibiloni MD, Tur JA. Prevalence of overweight, obesity, abdominal-obesity and short stature of adult population of Rosario, Argentina. Nutr Hosp 2016; 33(5): 580.

35. Johnson W, Stovitz SD, Choh AC, et al. Patterns of linear growth and skeletal maturation from birth to 18 years of age in overweight young adults. Int J Obes 2012; 36(4): 535-541.

36. Pinhas-Hamiel O, Reichman B, Shina A, et al. Sex differences in the impact of thinness, overweight, obesity, and parental height on adolescent height. J Adolescent Health 2017, doi: 10.1016/j.jadohealth.2017.02.016.

37. Feller $\mathrm{S}$, Boeing $\mathrm{H}$, Pischon T. Body mass index, waist circumference, and the risk of type 2 diabetes mellitus: implications for routine clinical practice. Dtsch Arztebl Int 2010; 107(26): 470-476.

38. Marcadenti A, Fuchs SC, Moreira LB, et al. Accuracy of anthropometric indexes of obesity to predict diabetes mellitus type 2 among men and women with hypertension. Am J Hypertens 2011; 24(2): 175-180.

39. Cardozo ER, Dune TJ, et al. Knowledge of obesity and its impact on reproductive health outcomes among urban women. J Community Health 2013; 38(2): 261-267.

Tables: 4

Figures: 0

References: 39

Received: 03.02.2020

Reviewed: 05.05.2020

Accepted: 01.09.2020

Address for correspondence:

Mohammad Hassan Eftekhari, Ph.D.

Department of Clinical Nutrition

School of Nutrition and Food Sciences

Shiraz University of Medical Sciences

Shiraz

Iran

Tel.: +989177088717

E-mail: h_eftekhari@yahoo.com 